\title{
Occupational Noise Dose Reduction via Behavior Modification Using In-Ear Dosimetry among United States Air Force Personnel Exposed to Continuous and Impulse Noise
}

\author{
Jesse Trawick ${ }^{1,2}$, Jeremy Slagley ${ }^{1 *}$, Robert Eninger ${ }^{1}$ \\ ${ }^{1}$ Department of Systems Engineering and Management, Air Force Institute of Technology, Wright-Patterson Air Force Base, \\ Ohio, USA \\ ${ }^{2} 99^{\text {th }}$ Civil Engineer Squadron, Nellis Air Force Base, Nevada, USA \\ Email: *jeremy.slagley@afit.edu
}

How to cite this paper: Trawick, J., Slagley, J. and Eninger, R. (2019) Occupational Noise Dose Reduction via Behavior Modification Using In-Ear Dosimetry among United States Air Force Personnel Exposed to Continuous and Impulse Noise. Open Journal of Safety Science and Technology, 9, 61-81.

https://doi.org/10.4236/ojsst.2019.92005

Received: March 28, 2019

Accepted: May 31, 2019

Published: June 3, 2019

Copyright $\odot 2019$ by author(s) and Scientific Research Publishing Inc. This work is licensed under the Creative Commons Attribution International License (CC BY 4.0).

http://creativecommons.org/licenses/by/4.0/

\begin{abstract}
In-ear dosimetry and noise exposure feedback were used to modify worker attitude and behavior regarding hearing protection use. The study specifically addressed whether providing in-ear noise exposure data to workers resulted in a reduction in average noise dose rate equivalent continuous levels. Nineteen combat arms instructors (impulse noise group) and heavy equipment operators (continuous noise group) working for the United States Air Force volunteered to participate in a six-month field study using in-ear dosimeters to collect daily noise level data. Participants served as their own control group, receiving periodic noise exposure feedback reports in the latter half of the study only. The control and feedback phase noise exposure data were examined using analysis of variance for differences that could be indicative of more effective hearing protection device use. Additionally, a 7-point Likert survey was used to monitor worker attitude towards hearing protection use, and worker medical histories were examined for evidence of previous hearing loss. Overall, this research found a significant reduction in noise dose rate equivalent continuous level $(-2.5 \mathrm{~dB}$ with $\mathrm{p}=0.019)$ for the continuous noise group following periodic noise exposure feedback on in-ear noise levels. This effect was not detected at the individual level due to limited samples. No effect was detected in the impulse noise population, likely due to limitations of dosimeter technology in response to impulse noise. No correlation between worker attitudes towards hearing protection and noise dose rate equivalent continuous level was detected for either group (continuous $p=0.249$; impulse $\mathrm{p}=0.478$ ). While workers reported that in-ear dosimeters and noise exposure
\end{abstract}


feedback helped them control their exposures, few reported using immediate feedback functions to control noise exposures within a work shift. These results indicate that in-ear dosimetry and noise exposure feedback could provide an effective tool to reduce worker noise exposures over time. However, advances in dosimeter technology are necessary before it can be evaluated for impulse noise. Additionally, further research is necessary to understand the link between worker attitude and hearing protection device use.

\section{Keywords}

Field-Microphone in Real Ear, Hearing Protection, In-Ear Dosimetry, Noise

\section{Introduction}

The overall prevalence of noise-related illnesses among United States Air Force personnel could partly be attributed to the limitations of using noise reduction ratings (NRRs) to estimate at-ear noise levels under hearing protection devices (HPDs); however, the Air Force does not currently have an established procedure for performing measurement of at-ear noise levels directly. The lack of at-ear noise level data makes it difficult to determine how effective HPDs are at mitigating noise exposures or what excess health risk is associated with improper HPD use. Additionally, for impulse noise, the auditory risk models recommended by Air Force Instruction (AFI) 48-127 and MIL-STD-1474E have recently been shown to contradict each other, providing recommended allowable exposures numbers that differ drastically [1]. Due to equipment and resource limitations, calculations of these allowable exposures often require blanket assumptions that may underestimate the risk of hearing damage for small arms gunfire or complex noise, consisting of both impulse and continuous noise sources [1] [2]. Given the current inaccuracies of the models for impulse and complex noise and conflicting auditory risk approximations, there has been increased interest in at-ear dosimetry measured at the eardrum. This measurement location bypasses the need for assumptions and correction factors for microphone placement, potentially providing a more accurate representation of auditory risk of hearing loss [2]. Smalt et al. [2] described the assumptions required to estimate at-the-eardrum hearing risk from HPD attenuation data applied to area or personal noise exposure. They recognized the utility of in-ear noise dosimetry to estimate risk at the eardrum, bypassing the transfer function calculations [2].

The largest effort to address the limitations of current methods of performing noise exposure assessments has been through a series of studies at Alcoa Incorporated, an aluminum manufacturing company operating across the United States. Prior to 2005, Alcoa utilized a hearing conservation program (HCP) that exceeded the requirements dictated by the US Occupational Safety and Health Administration (OSHA), to include yearly fit tests for earplug-type HPDs and an 
action level of $82 \mathrm{dBA}$ in an attempt to control worker noise exposures [3] [4]. Despite these efforts, threshold shifts continued to occur at an average rate of 1.7 dB per year [5].

In March of 2005, Alcoa incorporated daily exposure monitoring utilizing a Field Microphone in Real Ear (F-MIRE) dosimeter into their HCP at one of their factories in Washington state [3]. All workers who demonstrated a $5 \mathrm{~dB}$ permanent threshold shift (PTS) were required to utilize this equipment to continue employment. A group of Yale researchers conducted a retrospective analysis of audiometric data from 2000 to 2010, which included both pre- and post-intervention threshold shift data [5]. The results of this study showed that the average threshold shift was reduced from 1.7 to $-0.5 \mathrm{~dB} /$ year after beginning continuous monitoring utilizing F-MIRE dosimetry, which indicates that use of this method assisted in mitigating exposures to the point that even temporary threshold shifts (TTSs) were being addressed. When compared to workers at other Alcoa factories, the intervention group achieved a $1.7 \mathrm{~dB}$ per year greater reduction in threshold shift rates than their peers [5].

Following the compulsory study in Washington, a voluntary study was conducted at three additional Alcoa factories utilizing the same system [6]. Subjects were offered a cash incentive for active participation over the course of 6 months. The results of this study indicated that utilizing daily monitoring with F-MIRE devices significantly reduced the percentage of exposures exceeding 85 dBA time-weighted average (TWA) from $14 \%$ to $8 \%$ and exposures over $90 \mathrm{dBA}$ TWA from $4 \%$ to $2 \%$. Additionally, by collecting at-ear measurements and providing that data to workers, worker self-efficacy regarding hearing health was improved. Of those who continuously used the F-MIRE dosimeter, " $89 \%$ believed it helped them control their noise exposure and $96 \%$ say it helped them preserve their hearing" [6].

While the Alcoa studies do show consistent support both for the use of frequent exposure monitoring and intervention, and the use of F-MIRE dosimeters as an integral part of an HCP, there are limits to the generalization of these results. First, the subjects of these studies tended to be older and already exhibiting symptoms of NIHL [5] [7]. Research shows that NIHL accelerates at a faster rate during the first 10 to 15 years of exposure [8]. The possibility exists that the reduction in threshold shifts among the subjects could be partially attributed to normal slowing of hearing loss due to age. Second, the noise exposures measured during these studies all came from a manufacturing environment, where ambient noise levels are rather consistent over a given shift for a given task. Utilizing this system in different work environments or on batch processes may yield different results. Lastly, the use of the F-MIRE dosimeters was paired with a significant training and supervisory intervention regarding proper use of hearing protection [5]. These efforts, rather than the use of the F-MIRE dosimeters, could explain the results of these studies. Therefore, more research utilizing F-MIRE dosimeters in a military population, with types of noise exposures other 
than manufacturing and in absence of other extensive intervention measures is necessary.

A recent field study compared F-MIRE to on-body impulse noise measurements to explore the factors affecting noise attenuation. Researchers found that the measured estimate of dose in the ear canal varied more than would be expected by assuming an impulse noise insertion loss and applying it to the pressure wave. They successfully demonstrated a wearable F-MIRE dosimeter designed for impulse noise environments [9]. Another research effort occurred in a hospital environment in Brazil among hospital nutrition staff. In addition to the F-MIRE dosimeter, the Brazilian study measured the ambient noise dose on the shoulder to evaluate the effectiveness of the HPDs worn by the subjects. This study, however, was cross-sectional rather than longitudinal; therefore, no conclusions can be drawn on whether the devices influenced workers' noise exposures levels [10].

Given the state of research concerning F-MIRE noise dosimetry, this study focused on utilizing these devices on a military population and on both continuous and impulse noise exposures.

F-MIRE dosimeters have been shown not only as a useful option for estimating risk, the previously cited studies also suggest they can be useful to help control risk. The hierarchy of controls for occupational health hazards rightly demands the implementation of engineered or administrative controls before resorting to personal protective equipment. However there are many situations where personal protective equipment is part of the appropriate suite of controls. Industrial hygienists often prescribe HPDs for noise hazards, but HPD effectiveness is a function of individual motivation to use them correctly and consistently.

The subject of motivation is one that has received significant attention-both inside of industrial hygiene and in general. How does one create an organizational culture that encourages individuals, with all their quirks and differences, to uniformly act in a way that may deviate from their natural inclinations? In the case of occupational health and safety, how does one get a worker to put their long-term health above more immediate concerns such as the job task, comfort, or speed? For occupational noise exposures that cannot be completely mitigated through engineering controls, the worker's motivation to protect themselves by using HPDs consistently and effectively is often the last line of defense against NIHL. Thus, it is imperative that an organization understand worker motivation and the factors that have the greatest impact on proper HPD use. There are several theories applied to understand individual motivation in making health-related decisions.

The Health Belief Model (HBM) was developed by the US Public Health Service in the 1950's and has been widely used in both practice and research to this day [11]. The theory of planned behavior (TPB) has been applied to hearing research in coal mines [12]. These models generally hinge on a perception of the possible benefit of an action. The attitude-behavior relation has long been a sub- 
ject of much study in psychology, with the tripartite theory of attitudes being one of the oldest and most prominent areas of research. The tripartite theory of attitudes dates back to the early 1960 's, when it was first theorized that attitudes were made up of affective, cognitive and behavioral components [13]. The tripartite theory of attitudes has undergone several transformations since first conceived, however, the core concepts remain relatively constant. First, the affective component relates to an individual's beliefs and feelings towards an attitude object, while cognitive attitudes are rooted in thoughts and reasoning towards an attitude object [13] [14] [15] [16]. The behavioral component refers to responses and actions towards the attitude object. Each of these components is considered separable and independently measurable, although they do have high correlation with one another [13].

In the prediction of behavior, the general consensus is that people seek to maintain consistency in affect, cognition, and behavior. This means that individuals that have high consistency in the affective and cognitive components of their attitude are more likely to behave in line with those components. This concept, called Affective Cognitive Consistency (ACC), has been studied extensively and received significant support [15] [17] [18]. The largest amount of application research in using the tripartite theory of attitudes is in effectiveness of behavioral persuasion using cognitively or affectively focused advertising [19] [20]. Studies of the job satisfaction-job performance relationship have also been explored and found support for the moderating role of ACC in the attitude-behavior relationship [21]. There has, however, been no notable research concerning affective and cognitive attitudes and their relationship to occupational safety behavior. Given the current lack of occupational safety research utilizing the tripartite theory of attitudes, there is a need to further explore this area of research. Additionally, of the models explored so far, the tripartite theory of attitudes holds the most promise for a study of this size. The primary constructs (affect and cognition) should present themselves strongly and provide enough nuance to be detected even in a small study group, unlike HBM or TPB. By ranking an individual's attitude relative to their peers, subjects can be stratified into tiers of more or less motivated individuals, which should correlate with HPD use effectiveness. In the case of a mismatch in ACC, either the cognitive or affective component should still be a predictor for HPD use.

For noise exposure, the US Air Force uses a criterion level of $85 \mathrm{dBA}$ time-weighted average and a $3 \mathrm{~dB}$ exchange rate. Workers exposed at or above $85 \mathrm{dBA}$ are recommended for enrolment in a hearing conservation program. The Air Force has an effective HCP with expert HPD selection and fitting, annual training, HPD enforcement of use, and annual audiograms [22]. An epidemiologic study of hearing loss rates by job classifications indicated that $2.5 \%$ to 8.3\% of Air Force personnel experience permanent hearing loss. While similar to civilian job classifications, there are some with little expected noise exposure (e.g., contracting, medical) that experience higher rates than their civilian coun- 
terparts [23]. However, Air Force and Department of Defense workers still experience an exceptional level of morbidity from hearing-related illnesses, with NIHL or tinnitus comprising by far the most prevalent compensated disability, making up $12.7 \%$ of all disabilities [24].

This project attempted to replicate the foundry study using in-ear dosimeters on continuous and impulse noise-exposed Air Force workers, and included an attitude questionnaire to assess motivation in HPD use.

\section{Methods}

\subsection{Attitude Assessment by Participant Questionnaire}

In order to understand worker motivation and health behavior, a 7-point Likert questionnaire was administered at three points during the field study: once during recruitment, once at the end of the control phase, and again at the end of the feedback phase. The questionnaires collected basic subject information (age, military rank, gender, etc.), information on work habits and noise exposures, and worker attitude towards hearing protection device use and hearing health. The worker attitude questions were written based on the Affective-Cognitive Consistency (ACC) attitude-behavior model, particularly research on job performance by Schleider, Watt, and Greguras [21]. Additionally, questions about the usability of the F-MIRE dosimeter were included in the questionnaire administered at the end of the field study. The questionnaire asked for a Likert scale value of 1 to 7 with 1 being "strongly disagree" and 7 being "strongly agree". Questions were worded in such a way that the higher number corresponded to a more positive perception of the usability of the F-MIRE dosimeter. A copy of the final questionnaire is provided as a supplemental file.

In order to establish construct validity for the worker attitude questions, three subject matter experts were asked to categorize each question as either affectively or cognitively focused. Only questions that achieved concurrence between all three experts were utilized in data analysis. Of the 31 original questions, thirteen affective and nine cognitive questions remained. Each construct (affect and cognition) had a final Cronbach's alpha of 0.8607 and 0.8698 , respectively. Removing any one question had no significant impact on overall reliability of either question set.

\subsection{Field Study}

This field study was broken into three phases: recruitment phase, control phase, and feedback phase. These phases did not coincide for both the continuous and impulse noise populations and phase length was adjusted due to volunteer work schedules. However, the general framework remained constant and the study did not exceed six months overall. Each phase is briefly explained in the sections below.

\subsubsection{Recruitment Phase}

In this phase, subjects were recruited and evaluated to determine if they could 
safely proceed with the rest of the field study without impacting their ability to work in high-noise environments. Subjects were recruited from a population of combat arms instructors and heavy equipment operators that were collocated at an Air Force base with the researchers. Air Force combat arms instructors teach military personnel how to maintain and use their firearms. They typically teach several classes each week with a class culminating in a weapons firing exercise on the firing range. The instructors are routinely exposed to the impulse noise from weapons firing. Personal noise dosimetry performed by the servicing industrial hygienists on the combat arms instructors resulted in time-weighted average (TWA) exposures of 115 deciBels, A-weighted (dBA). Within this impulse noise-exposed combat arms instructor group, there were some active duty military personnel exposed very routinely, and some Air Force Reserve personnel. The Air Force reservists perform some other job most of their working lives, but report for combat arms instructor duties two days per month, and for a two-week period usually in the summers. Therefore the reservists' impulse noise exposures are intermittent. When they are on duty one weekend per month, they have normal high level impulse exposures. For the rest of their working lives they may have some or no occupational noise exposure.

The heavy equipment operators performed routine grounds maintenance across the base. For the period of the study, their primary noise exposure was continuous noise from grass-mowing equipment. Their TWA noise dose equivalent level $\left(\mathrm{L}_{\text {eq }}\right)$ was estimated at $90 \mathrm{dBA}$. These particular populations were selected due to having regular and significant noise exposures. In order to participate, the volunteer had to be at least 18 years old, must have been either a military or civilian Air Force employee, and must have been projected to continue their duties at that base for at least 6 months. No incentive or condition for continued employment was provided for participation and supervisors were not permitted to influence recruitment.

During recruitment, subjects underwent a Personal Attenuation Rating (PAR) test using the FitCheck Solo system (ProtectEar USA, Las Vegas, Nevada) to evaluate whether sufficient attenuation could be achieved using the in-ear dosimeter earplugs. Subjects that could not obtain at least as much attenuation as required by their hearing conservation program were not permitted to continue with the field study. For instance, the grounds maintenance continuous group had a TWA $\mathrm{L}_{\text {eq }}$ of $90 \mathrm{dBA}$, so they required a PAR of at least $5 \mathrm{~dB}$ to reduce their $\mathrm{L}_{\mathrm{eq}}$ to no more than $85 \mathrm{dBA}$.

\subsubsection{Control Phase}

During the control phase, each subject's baseline noise exposure profile was established without intervention or treatment from the research team. Subjects were provided an F-MIRE dosimeter (QuietDose Exposure Smart Protector, Howard Leight, San Diego, California) to wear whenever noise exposures were expected. They were, however, not informed about any of the device feedback 
features and any visual indicators were obscured by taping over the readout screen. Any data collected during this phase was not provided to the subject until the start of the feedback phase.

The device was collected, data was downloaded, and calibration was performed on a weekly basis. While the goal of this phase was to collect six control data points per subject, this was not possible for all subject groups due to individual work schedules. In particular, Air Force Reserve participants only work one weekend per month, severely limiting the number of data points attainable in each phase of this study. In these cases, a decision to proceed to the feedback phase with less than six control data points was made with the understanding that it may hinder the ability to detect effects between phases.

\subsubsection{Feedback Phase}

At the start of the feedback phase, subjects were informed of all dosimeter feedback features, to include light-emitting diode (LED) lights and display information. Additionally, a report containing all noise exposure data collected during the control phase was provided to each individual. This report included data on shift length, percent noise dose, TWAs, and number of seconds the device read over $115 \mathrm{~dB}$ during a shift. At this point, as well as whenever an updated report was provided, subjects were allowed to ask questions about the metrics and their interpretation.

During the remainder of this phase, subjects continued to wear the F-MIRE dosimeter and were provided periodic feedback reports on their noise exposure levels in all previous work shifts. While the original intent of the study was to allow the subject to download device data themselves on a daily basis and receive immediate feedback, download errors in the commercial user interface limited this capability and threatened the effectiveness of the treatment. Instead, the researchers collected the devices on a weekly basis, downloaded the raw data manually, and provided an updated paper report before the start of the next work week. While this change limited the overall effectiveness of the treatment plan, it avoided frustrating the subjects such that they might lose faith in the data provided or use the device less to avoid the frequent errors.

\section{Results}

\subsection{Study Demographics}

Overall, 19 subjects, five grounds maintenance personnel and 14 combat arms instructors, volunteered to participate in the field study. The study population was $76 \%$ male and $24 \%$ female. There were $12 \%$ active duty military, $29 \%$ civilian, and 59\% reserve military. It should be noted that the study population contained more females than is typical of the general Air Force population on HCPs, which is closer to $9 \%$ [23]. Additionally, while the majority of volunteers were younger than 40 years of age, there were four individuals that were old enough to potentially exhibit normal presbycusis. Only one of those individuals, howev- 
er, reported being diagnosed with a permanent threshold shift (PTS). Finally, the majority of the study population was sampled from the Air Force Reserves, who express less frequent noise exposures due to their occupation in the Reserves and may have occupational noise exposures in their primary job. Only five individuals reported having a primary occupation that may involve high levels of noise exposure.

The subjects were also asked to describe their typical work week. The majority of the subjects reported a five day work week with between six and ten hour work days. The study population overall reported being noise exposed less days than they typically work, and less hours per day than they typically work. This trend supports the assumption of intermittent noise exposures for the study population. The majority of volunteers reported using both earplugs and muffs, which is expected due to the HCP of the combat arms instructors requiring double hearing protection.

In order to describe external factors that may influence this research, the subjects were also asked about their hobbies and other occupations which may involve high levels of noise exposure. Over half the study population reported having a noisy hobby, with $60 \%$ of those individuals engaging in firearms related activities. This statistic indicates that there are likely high levels of impulse noise that were external to this study and therefore were not measured. Additionally, two individuals reported having firearms related occupations outside of their Air Force duties, while three reported other occupations that involve high levels of continuous noise.

In the field study questionnaire, $12 \%$ of the subjects reported having been diagnosed with a PTS and $24 \%$ with tinnitus. When compared to data obtained from the Defense Occupational and Environmental Health Readiness System (DOERHS), which contains medical and occupational exposure data for all Air Force personnel, higher rates of PTS were discovered on record for the same subjects. The exact difference could not be verified due to some subjects declining to provide information required to access their medical records. This difference in reported and recorded PTS rates could be explained by a subject's reluctance to provide accurate medical information; however, it could also be attributed to the Air Force's policy to record a PTS if the member does not complete a follow-up exam after identifying a temporary threshold shift (TTS). Of those individuals whose medical records were accessed, one third had a TTS on record.

\subsection{Analysis of Variance (ANOVA) of Field Study Phases}

Dosimetry results varied by duration of exposure as well as the level and types of exposure. In order to normalize the variability, the firing range instructors' dose $\left(\% D_{85.3}\right)$ was converted to a percent dose rate per 1000 rounds fired $\left(\% D_{1000 \text { rounds }}\right)$, per Equation (1). The dose rate per 1000 rounds was converted to an equivalent continuous sound level per 1000 rounds ( $L e q_{1000 \text { rounds }}$ ) using Equation (2). 


$$
\begin{gathered}
\% D_{1000 \text { rounds }}=\left(\frac{\% D_{85.3}}{\# \text { of rounds fired }}\right) * 1000 \\
L e q_{1000 \text { rounds }}=10 * \log _{10}\left(\% D_{1000 \text { rounds }}\right)+85
\end{gathered}
$$

The continuous noise group was normalized to a percent noise dose rate per hour $\left(\% D_{h r}\right)$, per Equation (3). Similarly, the continuous noise dose per hour was converted to equivalent continuous sound level per hour $\left(\operatorname{Leq}_{h r}\right)$ with Equation (4).

$$
\begin{gathered}
\% D_{h r}=\left(\frac{\% D_{85.3}}{\text { shift duration in minutes }}\right) * 60 \\
\operatorname{Leq}_{h r}=10 * \log _{10}\left(\% D_{h r}\right)+85
\end{gathered}
$$

\subsubsection{Continuous Noise Group}

Researchers conducted an ANOVA test on the continuous noise dose rate blocked by individuals' subject identification (ID) and study phase. The overall full factorial model in Table 1 was significant $(p=0.0099)$, and the results in Table 2 indicate that both the individual subject and the study phase were significant ( $\mathrm{p}=0.0092$ and 0.019 , respectively). The interaction was not significant. Converting the dose rate to equivalent level, the results showed an overall group change in $L e q_{h r}$ of $-2.5 \mathrm{dBA} /$ hour when workers started receiving dose feedback. The overall model had an R-squared value of 0.313 ( 0.210 adjusted R-squared) and the sum of squares for the error was twice that of the model. This indicates that, while the factors included in the model were significant, there are other significant effects that were not measured that may be influencing the outcome. Additionally, the significant effects detected for subject ID highlights the fact that subject background and attitudes may continue to play a large part in worker safety and health behavior. The effects are also presented graphically in Figure 1.

One subject experienced significantly lower noise dose rates than two other individuals and about the same level of exposure as the fourth. This individual typically performed noisy tasks more intermittently than the other subjects, which could account for this difference in noise dose rate. While some of the overall noise dose reduction is likely attributable to this one factor, noise exposure feedback still played a significant role. The noise dose rate equivalent continuous level $\left(L e q_{h r}\right)$ reduction of $2.5 \mathrm{~dB}(\mathrm{p}=0.019)$ between the control and feedback phases was found after accounting for individual differences in the subjects. However, two individuals did see a non-significant reduction in the mean hourly dose equivalent continuous level of $3 \mathrm{~dB}$ and $6.4 \mathrm{~dB}$, with $\mathrm{p}$ values of 0.1299 and 0.0757 , respectively. Due to the small number of samples for these two subjects, the ANOVA test likely lacked the statistical power to effectively reduce the chance of Type II error occurring. If more samples were available for these individuals, there is a possibility that significance could be achieved. The remaining subjects' noise dose rate equivalent continuous levels between the control and feedback phases were similar, varying by only $\pm 1 \mathrm{~dB}$. 

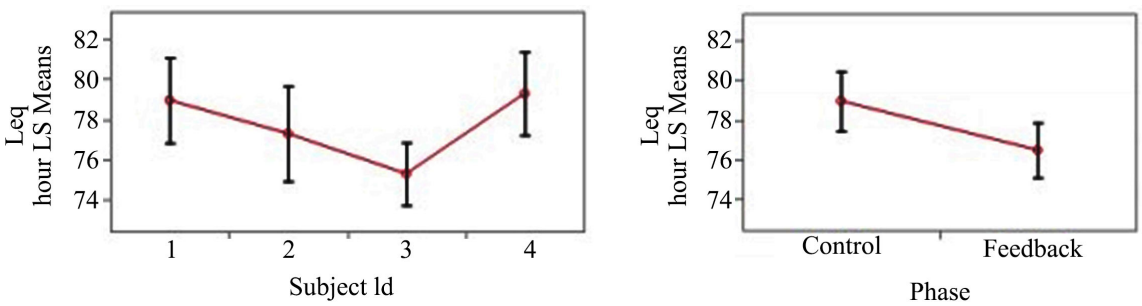

Figure 1. Effects of (a) Subject Identification (ID) and (b) Phase on Equivalent Sound Level per hour for the Continuous Noise Group.

Table 1. Full Factorial ANOVA and Effects for Continuous Noise Group.

\begin{tabular}{cccccc}
\hline Source & $\begin{array}{c}\text { Degrees of } \\
\text { Freedom }\end{array}$ & Sum of Squares & Mean Square & F Ratio & Prob $>$ F \\
\hline Model & 7 & 263.58 & 37.66 & 3.05 & 0.0099 \\
Error & 47 & 579.60 & 12.33 & & \\
C Total & 54 & 843.19 & & & \\
\hline
\end{tabular}

Table 2. ANOVA Results of Continuous Noise Group.

\begin{tabular}{cccccc}
\hline Source & $\begin{array}{c}\text { Degrees of } \\
\text { Freedom }\end{array}$ & Sum of Squares & Mean Square & F Ratio & Prob $>$ F \\
\hline Subject & 3 & 159.14 & 53.05 & 4.30 & 0.0092 \\
Phase & 1 & 72.73 & 72.73 & 5.90 & 0.019 \\
Subject ${ }^{\star}$ Phase & 3 & 84.31 & 28.10 & 2.28 & 0.0917 \\
\hline
\end{tabular}

\subsubsection{Impulse Noise Group}

There was no significant effect detected for the impulse noise group as a whole. As shown in Table 3 for the overall model, and Table 4 for the two factors in the model, neither subject nor phase appeared to have a measurable impact on noise dose rates. Overall, there was a nonsignificant increase in noise dose rate equivalent continuous levels for the impulse group of about $2.6 \mathrm{~dB}$ between the control and feedback phase.

The only significant result for an individual was a $10.5 \mathrm{~dB}$ increase at a p-value of 0.0083 , which is the opposite of the hypothesized effect. Additionally, most of the remaining individuals in the impulse noise group experienced a non-significant increase in their noise dose rate equivalent continuous level of between $2.1 \mathrm{~dB}$ and $5.2 \mathrm{~dB}$. Only one subject had a reduction in noise dose rate equivalent continuous level of about $8.9 \mathrm{~dB}$; although, only 5 total samples were available for both the control and feedback phase for that subject. Like the individuals in the continuous noise group, the sample size was not large enough to obtain the statistical power necessary to mitigate Type II error.

Some other results that were surprising were the degree of variability in the data. As an example, one impulse noise subject had a range of F-MIRE doses from $14 \%$ to $2792 \%$ under double hearing protection. This caused us to look deeper into the performance of the F-MIRE system in a laboratory setting. 
Table 3. Full Factorial ANOVA and Effects for Impulse Noise Group.

\begin{tabular}{cccccc}
\hline Source & $\begin{array}{c}\text { Degrees of } \\
\text { Freedom }\end{array}$ & Sum of Squares & Mean Square & F Ratio & Prob $>$ F \\
\hline Model & 13 & 704.59 & 54.20 & 1.30 & 0.2578 \\
Error & 36 & 1500.78 & 41.69 & & \\
C Total & 49 & 2205.36 & & & \\
\hline
\end{tabular}

Table 4. ANOVA Results of Impulse Noise Group.

\begin{tabular}{cccccc}
\hline Source & $\begin{array}{c}\text { Degrees of } \\
\text { Freedom }\end{array}$ & Sum of Squares & Mean Square & F Ratio & Prob $>$ F \\
\hline Subject & 6 & 248.49 & 41.42 & 0.99 & 0.4445 \\
Phase & 1 & 77.20 & 77.20 & 1.85 & 0.182 \\
Subject * Phase & 6 & 286.80 & 47.80 & 1.15 & 0.356 \\
\hline
\end{tabular}

The combination F-MIRE dosimeter and earmuff (Impact Sport, Howard Leight, Smithfield, RI) used by the impulse noise group was tested at the National Institute for Occupational Safety and Health (NIOSH) impulse noise laboratory. It was observed on the acoustic test fixture (ATF) manikin that the stem of the F-MIRE earplug contacted the interior of the low-profile muff, and the cable from the plug's microphone to the dosimeter interfered with the seal of the earmuff pad. Testing indicated that the F-MIRE microphone did not match the phase of the impulse waveform measured at the "eardrum" microphone of the ATF manikin. Researchers hypothesized that the F-MIRE microphone housed in the earplug stem was responding to the impulse at the stem more profoundly than the interior of the ATF ear canal. The difference in phase was not observed with a deeper cup earmuff where the ear plug stem did not contact the interior of the muff.

This effect greatly amplifies the impact of air leaks on measured noise levels, inflating the highest recorded noise levels artificially and increasing the weight those data points had on the final outcome. This effect is not always expected to occur and is difficult to account for without detailed information on the subject's daily earmuff fit. Additionally, some subjects may experience this effect more than others due to physiological differences in ear canal sizes that could make achieving sufficient earplug insertion depth more difficult, thus increasing the likelihood of contact with the earmuff and a broken seal. This may explain some of the observed variability in impulse noise dose measurements which also overwhelmed the ANOVA model.

\subsubsection{Worker Attitude Analysis}

According to the results of ANOVA analyses on the study phase and Affective-Cognitive Consistency (ACC) attitude effect on the noise dose rate equivalent continuous level, there was no detectable effect of any of the tripartite theory constructs or feedback on average noise dose rates for either the conti- 
nuous or impulse noise groups ( $\mathrm{p}=0.249,0.478$, respectively) as shown in Table 5 and Table 6 for the overall attitude models. This result could either be a true indicator of the effect, or, like previous analyses, be dependent on lack of statistical power due to small sample size and Type II error. No support was found for the moderating effects of affect, cognition or affective-cognitive consistency on HPD performance, as direct effects were not detected for either the moderator or independent variables.

When asked to rate the ease of use, effectiveness, and comfort of the F-MIRE device itself, respondents generally had a positive impression of the device and the usefulness of the noise reports. However, as seen in Table 7, subjects responded negatively (a score below 4) to both questions about if they used the immediate feedback to help control noise exposures from moment to moment. This trend is further supported by verbal accounts by the subjects to the researchers. Several individuals reported that the noise reports were useful and interesting, but they were unlikely to check the device during their work shift to see if they were approaching noise exposure limits.

Table 5. Full Factorial ANOVA of Phase and Attitude Effects for Continuous Noise Group.

\begin{tabular}{cccccc}
\hline Source & Degrees of Freedom & Sum of Squares & Mean Square & F Ratio & Prob $>$ F \\
\hline Model & 2 & 19.08 & 9.54 & 1.86 & 0.249 \\
Error & 5 & 25.69 & 5.14 & & \\
C Total & 7 & 44.77 & & & \\
\hline
\end{tabular}

Table 6. Full Factorial ANOVA of Phase and Attitude Effects for Impulse Noise Group.

\begin{tabular}{cccccc}
\hline Source & Degrees of Freedom & Sum of Squares & Mean Square & F Ratio & Prob $>$ F \\
\hline Model & 2 & 25.81 & 12.91 & 0.79 & 0.478 \\
Error & 11 & 179.66 & 16.33 & & \\
C Total & 13 & 205.47 & & & \\
\hline
\end{tabular}

Table 7. F-MIRE Usability Survey Response Summary.

\begin{tabular}{ccc}
\hline Question & $\begin{array}{c}\text { Average } \\
\text { Score }\end{array}$ & $\begin{array}{c}\% \text { Positive } \\
\text { Response }\end{array}$ \\
F-MIRE earplugs are comfortable to wear. & 4.9 & $58 \%$ \\
F-MIRE dosimeter is easy to use. & 6.2 & $92 \%$ \\
I check the dosimeter to see what my dose is. & 5.2 & $67 \%$ \\
When the red light comes on, I adjust my HPDs. & 2.7 & $17 \%$ \\
\hline
\end{tabular}

a. Field Microphone in Real Ear (F-MIRE) dosimeter usability survey was administered to subjects at the end of the study. The percent positive response was the number of responses ranked 4 or above divided by the total responses for that question. 
However, it should be noted that the subjects were not given full responsibility for the function of the device, due to data download errors. If the subjects were required to perform their own data collection and encountered similar errors, their overall impression of the device would likely be less positive than reported in this study.

\section{Discussion}

During this study, limited support for the use of in-ear dosimetry and periodic noise exposure feedback to reduce occupational noise exposures was found in the continuous noise populations $(-2.5 \mathrm{~dB}$ at $\mathrm{p}=0.019)$. This effect only manifested itself at the aggregated group level, likely due to the low number of samples per individual reducing the statistical power necessary to detect effects for a single participant. The lack of samples is due to the intermittent nature of the participant's noise exposures, wherein they are only exposed a few days each week, and the relatively short nature of this study. In order to better establish exposure trends over time, it would be better to follow a group of workers over a period of a few years, though worker turnover would likely become a significant factor.

For the impulse noise group, no significant effect was detected at either the group or individual level. However, this result could be explained by signal interference caused when an impulse is allowed to bypass the earmuffs through airgaps and interact with microphone stem of the dosimeter. This interference would cause the highest noise levels measurements, attained when the earmuff seal is broken, to be artificially inflated and not representative of actual in-ear noise levels. Additionally, noise signal clipping and slow microphone response continue to be a challenge for in-ear dosimeters. Many improvements in this area have already been made and should continue to progress to better understand impulse noise exposures [2] [9].

This study did not find any correlation between worker attitude and noise dose rate equivalent continuous levels or noise exposure feedback effectiveness. Low number of volunteers was the most significant factor, affecting the ability to detect effects which could be present but small. While the researchers could have administered the attitude surveys more frequently to increase the number of data points, this would have degraded data quality as participants become less interested in completing the survey repeatedly. The better alternative would be to increase the number of participants by drawing from a larger population. Volunteerism and accessibility to subjects with significant noise exposures was a challenge for this study, as the initial population selected was relatively small and few subjects from that population volunteered to participate. Introducing an incentive program could have increased volunteer participation, although that may have introduced a confounding factor that would need to be accounted for in the outcome.

Another major limitation for this study was data download issues for the 
equipment used. While the researchers did develop a workaround that mitigated effects on data quality, this ultimately reduced the frequency that the participant received feedback on their noise exposure levels. As originally conceived, the worker would perform data downloads at the end of every shift and receive immediate feedback while the recollection of their actions was still fresh. This would allow them to reflect on their personal behaviors that may have led to increased or reduced noise levels and modified their behaviors accordingly. With the weekly schedule utilized in this study, the subject may be able to identify trends but might not be able to recollect what actions they took that resulted in that increased or decreased noise dose. This effect severely limited the efficacy of this study's treatment and may have resulted in less pronounced reductions in noise dose rate equivalent continuous levels.

Lastly, while subjects reported positive impressions of the device and noise dose reports, none of the subjects in this study reported checking the device during the shift. This result has implications for both equipment design and implementation of a hearing conservation program, namely that both should focus on end of shift feedback versus immediate feedback functions. These features are more likely to be used by workers and result in the desired outcome of reducing noise dose. Additionally, the equipment used in this study may not be best suited for this particular application. Other commercial options have been developed that provide logs of noise dose levels throughout a shift, allowing the worker to better pinpoint a particular task or action that contributes most of their noise dose. This additional information may increase the efficacy of noise exposure feedback in modifying worker behavior and decreasing noise dose levels.

\section{Conclusion}

In-ear noise dosimetry and noise exposure feedback could provide a useful tool for evaluating occupational noise exposures and motivating individuals to improve their HPD use in a well-structured HCP. In this research effort, support was found for the correlation between in-ear noise dose reports and noise dose equivalent continuous level reduction in a population of workers exposed to continuous noise $(-2.5 \mathrm{~dB}$ at $\mathrm{p}=0.019)$. This effect was not detected at the individual level, however, due to limited available data. Further advancements in dosimeter technology and its response to impulse noise are necessary before the efficacy of in-ear dosimetry and periodic noise exposure feedback can be evaluated for impulse noise. While individual differences were found to be a significant contributor to noise dose equivalent continuous levels in the continuous noise group, no correlation was detected between a subject's affective or cognitive attitude towards hearing protection and their noise dose rate equivalent continuous level. Further research is necessary to better understand the link between an individual's attitude and their HPD use. Additionally, while subjects reported positive impressions of the in-ear dosimeter and feedback reports, only a few reported using immediate feedback functions to control their noise exposure. 
Future research on noise dosimetry and its impact on HPD use should emphasize end-of-shift feedback over immediate feedback functions. This study was limited by numbers of volunteers and reliability of the dosimetry equipment. Follow-on research should attempt to incorporate more subjects from broader occupational environments.

\section{Acknowledgements}

This research was funded by a faculty research seed grant from the Air Force Institute of Technology (\#2016-244). Human subjects research conducted under Air Force Research Laboratory Institutional Review Board protocol FWR20170071Hv1.02. The F-MIRE manufacturer, Honeywell (owner of Howard Leight), loaned us 10 dosimeters to start the project. We gratefully acknowledge the voluntary participants in the study. We would also like to thank the men and women of the Wright-Patterson Air Force Base, Ohio, Bioenvironmental Engineering Flight. Dr. Elizabeth McKenna and Maj Daniel Williams of the United States Air Force School of Aerospace Medicine (USAFSAM) Public Health Consultation Division provided audiological services for the project. CAPTs William Murphy and Chucri Kardous of the National Institute for Occupational Safety and Health generously supported the project with analysis of the performance of the equipment in impulse noise environments. Mr. Andrew Wells, Mr. Austin Szekacs, and Staff Sergeant Adam Whiteman from the USAFSAM Occupational and Environmental Health Consultation Division also helped collect and analyze impulse noise data.

\section{Disclaimer}

This document is the work of the authors and does not represent the position of the United States Department of Defense or the United States Air Force.

\section{Conflicts of Interest}

The authors declare no conflicts of interest regarding the publication of this paper.

\section{References}

[1] Canadian Department of National Defence (2015) A Comparison of Metrics for Impulse Noise Exposure Analysis of Noise Data from Small Calibre Weapons, by A. Nakashima (Report \#DRDC-RDDC-2015-R243). Defence Research and Development Canada, November 2015.

[2] Smalt, C.J., Lacirignola, J., Davis, S.K., Calamia, P.T. and Collins, P.P. (2017) Noise Dosimetry for Tactical Environments. Hearing Research, 349, 42-54. https://doi.org/10.1016/j.heares.2016.11.008

[3] Michael, K., Tougaw, E. and Wilkinson, R. (2011) Role of Continuous Monitoring in a Hearing Conservation Program. Noise and Health, 13, 195-199. https://doi.org/10.4103/1463-1741.77204

[4] Neitzel, R.L., Galusha, D., Dixon-Ernst, C. and Rabinowitz, P.M. (2014) Methods 
for Evaluating Temporal Trends in Noise Exposure. International Journal of Audiology, 53, S76-S83. https://doi.org/10.3109/14992027.2013.857438

[5] Rabinowitz, P.M., Galusha, D., Kirsche, S.R., Cullen, M.R., Slade, M.D. and Dixon-Ernst, C. (2011) Effect of Daily Noise Exposure Monitoring on Annual Rates of Hearing Loss in Industrial Workers. Occupational and Environmental Medicine, 68, 414-418. https://doi.org/10.1136/oem.2010.055905

[6] McTague, M.F., Galusha, D., Dixon-Ernst, C., Kirsche, S.R., Slade, M.D., Cullen, M.R. and Rabinowitz, P.M. (2013) Impact of Daily Noise Exposure Monitoring on Occupational Noise Exposures in Manufacturing Workers. International Journal of Audiology, 52, S3-S8. https://doi.org/10.3109/14992027.2012.743047

[7] Rabinowitz, P.M., Galusha, D., Dixon-Ernst, C., Clougherty, J.E. and Neitzel, R.L. (2013) The Dose-Response Relationship between In-Ear Occupational Noise Exposure and Hearing Loss. Occupational and Environmental Medicine, 70, 716-721. https://doi.org/10.1136/oemed-2011-100455

[8] Kirchner, D.B., Evenson, E., Dobie, R.A., Rabinowitz, P., Crawford, J., Kopke, R. and Hudson, T.W. (2012) Occupational Noise-Induced Hearing Loss. Journal of Occupational and Environmental Medicine, 54, 106-108. https://doi.org/10.1097/JOM.0b013e318242677d

[9] Davis, S.K., Calamia, P.T., Murphy, W.J. and Smalt, C.J. (2019) In-Ear and On-Body Measurements of Impulse-Noise Exposure. International Journal of Audiology, 58, S49-S57. https://doi.org/10.1080/14992027.2018.1534012

[10] Rocha, C.H., Longo, I.A., Moreira, R.R. and Samelli, A.G. (2016) Evaluation of the Hearing Protector in a Real Work Situation Using the Field-Microphone-in-Real-Ear Method. CoDAS, 28, 99-105. https://doi.org/10.1590/2317-1782/20162014146

[11] Champion, V.L. and Skinner, C.S. (2008) The Health Belief Model. In: Glanz, K., Rimer, B.K. and Viswanath, K., Eds., Health Behavior and Health Education: Theory, Practice, and Research, 4th Edition, John Wiley \& Sons, New York, 45-62.

[12] Quick, B.L., Stephenson, M.T., Witte, K., Vaught, C., Booth-Butterfield, S. and Patel, D. (2008) An Examination of Antecedents to Coal Miners' Hearing Protection Behaviors: A Test of the Theory of Planned Behavior. Journal of Safety Research, 39, 329-338. https://doi.org/10.1016/j.jsr.2008.02.032

[13] Petty, R.E., Fabrigar, L.R. and Wegener, D.T. (2003) Emotional Factors in Attitude and Persuasion. In: Davidson, R.J., Scherer, K.R. and Goldsmith, H.H., Eds., Handbook of Affective Sciences, Oxford University Press, Cary, 752-772.

[14] Millar, M.G. and Tesser, A. (1986) Effects of Affective and Cognitive Focus on the Attitude Behavior Relation. Journal of Personality and Social Psychology, 51, 270-276. https://doi.org/10.1037/0022-3514.51.2.270

[15] Millar, M.G. and Tesser, A. (1989) The Effects of Affective-Cognitive Consistency and Thought on the Attitude-Behavior Relation. Journal of Experimental Social Psychology, 25, 189-202. https://doi.org/10.1016/0022-1031(89)90012-7

[16] Crites, S.L., Fabrigar, L.R. and Petty, R.E. (1994) Measuring the Affective and Cognitive Properties of Attitudes: Conceptual and Methodological Issues. Personality and Social Psychology Bulletin, 20, 619-634. https://doi.org/10.1177/0146167294206001

[17] Norman, R. (1975) Affective-Cognitive Consistency, Attitudes, Conformity, and Behavior. Journal of Personality and Social Psychology, 32, 83-91. https://doi.org/10.1037/h0076865

[18] Lavine, H., Thomsen, C.J., Zanna, M.P. and Borgida, E. (1998) On the Primacy of 
Affect in the Determination of Attitudes and Behavior: The Moderating Role of Affective-Cognitive Ambivalence. Journal of Experimental Social Psychology, 34, 398-421. https://doi.org/10.1006/jesp.1998.1357

[19] Haddock, G., Maio, G.R., Arnold, K. and Huskinson, T. (2008) Should Persuasion Be Affective or Cognitive? The Moderating Effects of Need for Affect and Need for Cognition. Personality and Social Psychology Bulletin, 34, 769-778. https://doi.org/10.1177/0146167208314871

[20] Ivanov, B., Pfau, M. and Parker, K.A. (2009) The Attitude Base as a Moderator of the Effectiveness of Inoculation Strategy. Communication Monographs, 76, 47-72. https://doi.org/10.1080/03637750802682471

[21] Schleicher, D.J., Watt, J.D. and Greguras, G.J. (2004) Reexamining the Job Satisfaction-Performance Relationship: The Complexity of Attitudes. Journal of Applied Psychology, 89, 165-177. https://doi.org/10.1037/0021-9010.89.1.165

[22] U.S. Air Force (USAF) (2016) Occupational Noise and Hearing Conservation Program (AFI 48-127). USAF, Washington DC.

https://static.e-publishing.af.mil/production/1/af_sg/publication/afi48-127/afi48-12 7.pdf

[23] Soderlund, L.L., McKenna, E.A., Tastad, K. and Paul, M. (2016) Prevalence of Permanent Threshold Shifts in the United States Air Force Hearing Conservation Program by Career Field, 2005-2011. Journal of Occupational and Environmental Hygiene, 13, 383-392. https://doi.org/10.1080/15459624.2015.1123814

[24] Veterans Benefits Administration (2018) Compensation. US Department of Veterans Affairs, Washington DC.

https://www.benefits.va.gov/REPORTS/abr/docs/FY17-Compensation.pdf 


\section{Occupational Noise Dose Reduction from Novel Dosimetry System among Air Force Combat Arms Personnel}

\section{Participant Questionnaire}

Instructions: Please complete the questionnaire as accurately as possible. Your identity will be coded to ensure confidentiality. Only the researchers approved by the study protocol will have access to your data. Your responses will not be shared with anybody outside the research team.

Name: Rank: Gender: Male/Female Subject \#:

Age:

Years of military service:

(Air Force Specialty Code (AFSC):

Have you been diagnosed with hearing loss (a permanent threshold shift) or tinnitus (a ringing or buzzing in the ears)? Yes No If so, what type and when?

\begin{tabular}{|c|c|c|c|c|c|c|c|}
\hline $\begin{array}{l}\text { For the next questions, please } \\
\text { answer using the Likert scale } \\
1-7 \text { with } 1 \text { being "strongly } \\
\text { disagee" and } 7 \text { being } \\
\text { "strongly agree". }\end{array}$ & $\begin{array}{l}\text { Strongly } \\
\text { disagree }\end{array}$ & 2 & 3 & $\begin{array}{l}\text { Neither } \\
\text { agree nor } \\
\text { disagree } \\
4\end{array}$ & 5 & 6 & $\begin{array}{l}\text { Strongly } \\
\text { agree }\end{array}$ \\
\hline $\begin{array}{l}\text { Wearing hearing protection in } \\
\text { noisy environments feels } \\
\text { natural. }\end{array}$ & 1 & 2 & 3 & 4 & 5 & 6 & 7 \\
\hline $\begin{array}{l}\text { I find wearing earplugs } \\
\text { uncomfortable. }\end{array}$ & 1 & 2 & 3 & 4 & 5 & 6 & 7 \\
\hline $\begin{array}{l}\text { I find wearing double hearing } \\
\text { protection unpleasant. }\end{array}$ & 1 & 2 & 3 & 4 & 5 & 6 & 7 \\
\hline \multirow[t]{2}{*}{ I dislike wearing earplugs. } & 1 & 2 & 3 & 4 & 5 & 6 & 7 \\
\hline & $\begin{array}{c}\text { Strongly } \\
\text { disagree }\end{array}$ & 2 & 3 & $\begin{array}{l}\text { Neither } \\
\text { agree nor } \\
\text { disagree } \\
4\end{array}$ & 5 & 6 & $\begin{array}{c}\text { Strongly } \\
\text { agree } \\
\\
7\end{array}$ \\
\hline $\begin{array}{l}\text { I dislike wearing earmuff } \\
\text { hearing protection. }\end{array}$ & 1 & 2 & 3 & 4 & 5 & 6 & 7 \\
\hline $\begin{array}{l}\text { Putting in earplugs properly is } \\
\text { a hassle. }\end{array}$ & 1 & 2 & 3 & 4 & 5 & 6 & 7 \\
\hline $\begin{array}{l}\text { I value my hearing more than } \\
\text { my peers. }\end{array}$ & 1 & 2 & 3 & 4 & 5 & 6 & 7 \\
\hline $\begin{array}{l}\text { I would rather avoid noise } \\
\text { exposure than don hearing } \\
\text { protection. }\end{array}$ & 1 & 2 & 3 & 4 & 5 & 6 & 7 \\
\hline $\begin{array}{l}\text { If I can't hear someone talking } \\
\text { in a loud environment, I am } \\
\text { fine with removing my } \\
\text { earplugs to better hear them. }\end{array}$ & 1 & 2 & 3 & 4 & 5 & 6 & 7 \\
\hline $\begin{array}{l}\text { If I am only in a loud area for a } \\
\text { moment, I won't bother with } \\
\text { hearing protection. }\end{array}$ & 1 & 2 & 3 & 4 & 5 & 6 & 7 \\
\hline $\begin{array}{l}\text { I feel that wearing hearing } \\
\text { protection in loud } \\
\text { environments is important }\end{array}$ & 1 & 2 & 3 & 4 & 5 & 6 & 7 \\
\hline $\begin{array}{l}\text { There isn't a point to wearing } \\
\text { hearing protection. }\end{array}$ & 1 & 2 & 3 & 4 & 5 & 6 & 7 \\
\hline
\end{tabular}




\begin{tabular}{|c|c|c|c|c|c|c|c|}
\hline & $\begin{array}{c}\text { Strongly } \\
\text { disagree }\end{array}$ & 2 & 3 & $\begin{array}{c}\text { Neither } \\
\text { agree nor } \\
\text { disagree } \\
4\end{array}$ & 5 & 6 & $\begin{array}{c}\begin{array}{c}\text { Strongly } \\
\text { agree }\end{array} \\
7 \\
7\end{array}$ \\
\hline $\begin{array}{l}\text { If my shop is out of earplugs, I } \\
\text { will still perform a loud task } \\
\text { without them. }\end{array}$ & 1 & 2 & 3 & 4 & 5 & 6 & 7 \\
\hline $\begin{array}{l}\text { I encourage others to wear } \\
\text { hearing protection. }\end{array}$ & 1 & 2 & 3 & 4 & 5 & 6 & 7 \\
\hline $\begin{array}{l}\text { I ask for or find hearing } \\
\text { protection before entering a } \\
\text { loud area. }\end{array}$ & 1 & 2 & 3 & 4 & 5 & 6 & 7 \\
\hline $\begin{array}{l}\text { I am diligent about properly } \\
\text { using my hearing protection in } \\
\text { my normal duties. }\end{array}$ & 1 & 2 & 3 & 4 & 5 & 6 & 7 \\
\hline
\end{tabular}

\begin{tabular}{|c|c|c|c|c|c|c|c|}
\hline $\begin{array}{l}\text { For the next questions, please } \\
\text { answer using the Likert scale } \\
1-7 \text { with } 1 \text { being "strongly } \\
\text { disagree" and } 7 \text { being } \\
\text { "strongly agree". }\end{array}$ & $\begin{array}{l}\text { Strongly } \\
\text { disagree }\end{array}$ & 2 & 3 & $\begin{array}{l}\text { Neither } \\
\text { agree nor } \\
\text { disagree } \\
4 \\
4\end{array}$ & 5 & 6 & $\begin{array}{c}\begin{array}{c}\text { Strongly } \\
\text { agree }\end{array} \\
7 \\
7\end{array}$ \\
\hline $\begin{array}{l}\text { I only wear hearing protection } \\
\text { when I am reminded to. }\end{array}$ & 1 & 2 & 3 & 4 & 5 & 6 & 7 \\
\hline \multirow[t]{2}{*}{$\begin{array}{l}\text { I know when I need to wear } \\
\text { hearing protection and when I } \\
\text { don't. }\end{array}$} & 1 & 2 & 3 & 4 & 5 & 6 & 7 \\
\hline & $\begin{array}{c}\text { Strongly } \\
\text { disagree } \\
\\
1 \\
\end{array}$ & 2 & 3 & $\begin{array}{c}\text { Neither } \\
\text { agree nor } \\
\text { disagree } \\
4 \\
4\end{array}$ & 5 & 6 & $\begin{array}{c}\begin{array}{c}\text { Strongly } \\
\text { agree }\end{array} \\
7 \\
7\end{array}$ \\
\hline $\begin{array}{l}\text { Hearing protection is } \\
\text { important even in loud } \\
\text { environments at home } \\
\text { (mowing the lawn, using a } \\
\text { table saw, etc.) }\end{array}$ & 1 & 2 & 3 & 4 & 5 & 6 & 7 \\
\hline $\begin{array}{l}\text { I believe that everyone will } \\
\text { lose their hearing eventually, } \\
\text { regardless of using hearing } \\
\text { protection. }\end{array}$ & 1 & 2 & 3 & 4 & 5 & 6 & 7 \\
\hline $\begin{array}{l}\text { I am familiar with how to wear } \\
\text { earplugs. }\end{array}$ & 1 & 2 & 3 & 4 & 5 & 6 & 7 \\
\hline $\begin{array}{l}\text { I know wearing hearing } \\
\text { protection in loud } \\
\text { environments is important. }\end{array}$ & 1 & 2 & 3 & 4 & 5 & 6 & 7 \\
\hline $\begin{array}{l}\text { Wearing hearing protection is } \\
\text { an important part of my job. }\end{array}$ & 1 & 2 & 3 & 4 & 5 & 6 & 7 \\
\hline $\begin{array}{l}\text { I tend to forget to put in } \\
\text { hearing protection before I } \\
\text { perform a loud task. }\end{array}$ & 1 & 2 & 3 & 4 & 5 & 6 & 7 \\
\hline $\begin{array}{l}\text { It is important to take my time } \\
\text { when donning hearing } \\
\text { protection. }\end{array}$ & 1 & 2 & 3 & 4 & 5 & 6 & 7 \\
\hline
\end{tabular}




\begin{tabular}{|c|c|c|c|c|c|c|c|}
\hline & $\begin{array}{c}\text { Strongly } \\
\text { disagree }\end{array}$ & 2 & 3 & $\begin{array}{c}\text { Neither } \\
\text { agree nor } \\
\text { disagree } \\
4\end{array}$ & 5 & 6 & $\begin{array}{c}\begin{array}{c}\text { Strongly } \\
\text { agree }\end{array} \\
\\
7\end{array}$ \\
\hline $\begin{array}{l}\text { Wearing hearing protection in } \\
\text { loud environments is a rule } \\
\text { that must not be broken. }\end{array}$ & 1 & 2 & 3 & 4 & 5 & 6 & 7 \\
\hline $\begin{array}{l}\text { I believe everyone should take } \\
\text { care when putting in earplugs. }\end{array}$ & 1 & 2 & 3 & 4 & 5 & 6 & 7 \\
\hline $\begin{array}{l}\text { If I don't wear ear plugs in } \\
\text { loud environments all the } \\
\text { time, then I will lose my } \\
\text { hearing. }\end{array}$ & 1 & 2 & 3 & 4 & 5 & 6 & 7 \\
\hline $\begin{array}{l}\text { I don't see the long-term } \\
\text { benefits of wearing ear plugs. }\end{array}$ & 1 & 2 & 3 & 4 & 5 & 6 & 7 \\
\hline $\begin{array}{l}\text { The benefits of wearing } \\
\text { hearing protection outweigh } \\
\text { the disadvantages }\end{array}$ & 1 & 2 & 3 & 4 & 5 & 6 & 7 \\
\hline $\begin{array}{l}\text { It is worth it to wear } \\
\text { uncomfortable earplugs to } \\
\text { protect my hearing. }\end{array}$ & 1 & 2 & 3 & 4 & 5 & 6 & 7 \\
\hline $\begin{array}{l}\text { I correct peers who have not } \\
\text { properly donned hearing } \\
\text { protection. }\end{array}$ & 1 & 2 & 3 & 4 & 5 & 6 & 7 \\
\hline
\end{tabular}

\section{Survey questions specific to the F-MIRE dosimeter administered at the end of the study.}

\begin{tabular}{|c|c|c|c|c|c|c|c|}
\hline $\begin{array}{l}\text { For the next questions, please } \\
\text { answer using the Likert scale } \\
1-7 \text { with } 1 \text { being "strongly } \\
\text { disagree" and } 7 \text { being } \\
\text { "strongly agree". }\end{array}$ & $\begin{array}{l}\text { Strongly } \\
\text { disagree }\end{array}$ & 2 & 3 & $\begin{array}{l}\text { Neither } \\
\text { agree nor } \\
\text { disagree } \\
4\end{array}$ & 5 & 6 & $\begin{array}{c}\text { Strongly } \\
\text { agree } \\
\\
7\end{array}$ \\
\hline $\begin{array}{l}\text { QuietDose earplugs are } \\
\text { comfortable to wear. }\end{array}$ & 1 & 2 & 3 & 4 & 5 & 6 & 7 \\
\hline $\begin{array}{l}\text { The QuietDose dosimeter is } \\
\text { easy to use. }\end{array}$ & 1 & 2 & 3 & 4 & 5 & 6 & 7 \\
\hline $\begin{array}{l}\text { The QuietDose dosimeter } \\
\text { interferes with my work } \\
\text { performance. }\end{array}$ & 1 & 2 & 3 & 4 & 5 & 6 & 7 \\
\hline $\begin{array}{l}\text { I check the lights or display } \\
\text { periodically to see what my } \\
\text { dose rate is. }\end{array}$ & 1 & 2 & 3 & 4 & 5 & 6 & 7 \\
\hline $\begin{array}{l}\text { When the red light on the } \\
\text { dosimeter turns on, I adjust } \\
\text { my earplugs until the light } \\
\text { goes away. }\end{array}$ & 1 & 2 & 3 & 4 & 5 & 6 & 7 \\
\hline $\begin{array}{l}\text { Seeing a periodic noise dose } \\
\text { report positively affects my } \\
\text { hearing protection use. }\end{array}$ & 1 & 2 & 3 & 4 & 5 & 6 & 7 \\
\hline
\end{tabular}

